\title{
The Uptake of Methyl Vinyl Ketone, Methacrolein, and 2-Methyl-3-butene-2-ol onto Sulfuric Acid Solutions
}

\author{
Barbara Nozière, ${ }^{\dagger}$ Didier Voisin, ${ }^{\ddagger}$ Cheryl A. Longfellow, ${ }^{\S}$ Hans Friedli, Bruce E. Henry, and \\ David R. Hanson*
}

National Center for Atmospheric Research, Atmospheric Chemistry Division, Boulder, Colorado 80303

Received: September 30, 2005; In Final Form: December 19, 2005

\begin{abstract}
To investigate the link between molecular structure, reactivity, and partitioning of oxygenated organic compounds in acidic aerosols, the uptake of three compounds found in the atmosphere, methyl vinyl ketone (MVK), methacrolein (MACR), and 2-methyl-3-butene-2-ol (MBO), by sulfuric acid solutions has been measured using a rotated wetted-wall reactor (RWW) coupled to a chemical ionization mass spectrometer (CIMS). MVK was found to partition reversibly into 20-75 wt \% $\mathrm{H}_{2} \mathrm{SO}_{4}$ solutions, and we report Henry's law coefficients between 20 and $7000 \mathrm{M} \mathrm{atm}^{-1}$ over this range. A chemical reaction for MVK was likely responsible for the uptake observed for $80-96 \mathrm{wt} \% \mathrm{H}_{2} \mathrm{SO}_{4}$ solutions. We derive an upper limit to the aldol self-reaction rate coefficient for MVK in $80 \mathrm{wt} \%$ solution of $\sim 3 \mathrm{M}^{-1} \mathrm{~s}^{-1}$. MACR partitioned reversibly over most of the acidity range, and in contrast to that for MVK, the Henry's law coefficient was relatively independent of $\mathrm{H}_{2} \mathrm{SO}_{4}$ content. These differences indicate that the increase of the coefficient with acidity is likely due to the ability of the carbonyl molecule to form an enol. These results indicate that aldol condensation can be facile in concentrated sulfuric acid solutions, but it should be negligibly slow in dilute acid solutions such as tropospheric aerosols. MBO uptake could be explained by a Henry's law coefficient that decreases slightly as acid content varies from 20 to $55 \mathrm{wt} \% \mathrm{H}_{2} \mathrm{SO}_{4}$; we also measured the value in water, $70 \mathrm{M} \mathrm{atm}^{-1}$ at $298 \mathrm{~K}$. A steady-state uptake of $\mathrm{MBO}$ was observed onto $40-80 \mathrm{wt} \% \mathrm{H}_{2} \mathrm{SO}_{4}$ solutions, a reaction product was observed, and the reaction was tentatively identified as Pinacol rearrangement. Similar rearrangements could be at the origin of some substituted oxygenated species found in atmospheric aerosols.
\end{abstract}

\section{Introduction}

Recent studies have shown that the interactions of oxygenated organic compounds with acidic particles might play a role in the formation of secondary organic aerosols, ${ }^{1-5}$ in particular, for precursors for which gas-phase oxidation does not otherwise produce aerosols, such as isoprene and its oxidation products. ${ }^{4}$ Various explanations for these observations have been proposed, most emphasizing that the increase of aerosol mass was due to the formation of large molecular weight compounds by acidcatalyzed reactions. These hypotheses lack verification, and information on the identity and kinetics of the processes taking place in these media is missing. An extensive organic chemical literature is available on the acid-catalyzed reactions of organic compounds, ${ }^{6,7}$ yet most has a limited application for atmospheric conditions. On the other hand, the uptake of a few organic compounds by acidic solutions for atmospheric purposes has been reported. These studies focused on small species such as formaldehyde, ${ }^{8,9}$ acetaldehyde, ${ }^{10}$ acetone, ${ }^{11-15}$ and methanol ${ }^{16}$ and reported either the absence of reaction or a reactivity limited to very acidic conditions. A limited reactivity could be due to the simple molecular structures of these species, and more complex species may have a more significant chemistry. To explore this hypothesis, we studied the uptake of biogenic compounds found in the atmosphere, methyl vinyl ketone (MVK), methacrolein (MACR), and 2-methyl-3-butene-2-ol

\footnotetext{
$\dagger$ Rosenstiel School for Marine and Atmospheric Science, University of Miami, Florida.

$\doteqdot$ Laboratoire de Glaciologie, Grenoble, France.

$\S$ Central Oregon Community College, Bend, Oregon.
}

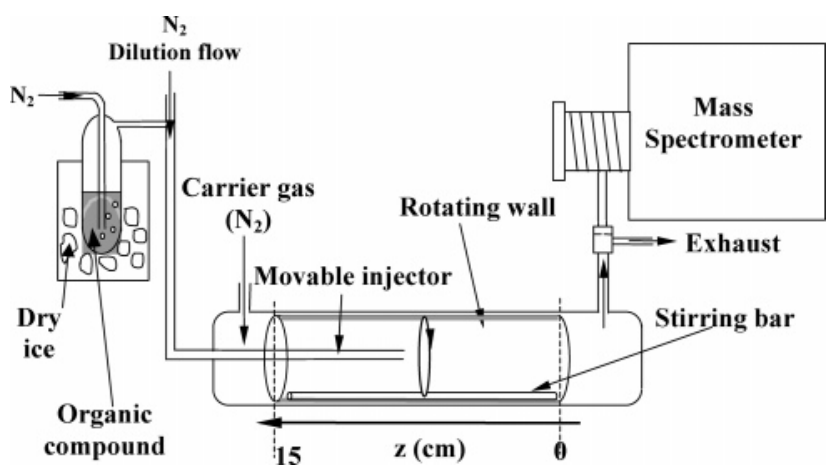

Figure 1. Schematic of the experimental setup.

(MBO) by aqueous sulfuric acid solutions. Values for the Henry's law coefficient and the rates of reactions were obtained from the observed uptakes, and to gain more insight on solubility and reaction, their variations with acid content were also investigated.

\section{Experimental Section}

Most of the experiments were performed in a rotated wettedwall reactor (RWW) coupled to a chemical ionization mass spectrometer (CIMS) as illustrated in Figure 1. The principle of the RWW has been described elsewhere, ${ }^{17,18}$ and this specific setup was described in a recent article. ${ }^{19}$ It consists of a glass cylindrical flow reactor equipped with an external glass jacket for thermostating and a rotatable inner cylinder (length $L=15$ $\mathrm{cm}$; radius $\rho=0.88 \mathrm{~cm}$ ) supporting the liquid film. Small 
volumes ( $V_{\text {liq }}=0.05-2 \mathrm{~mL}$ ) of water or sulfuric acid solutions were placed in the inner cylinder and rotated $(1-5 \mathrm{rpm})$ in order to maintain a thin film on the wall $(\sim 0.02 \mathrm{~cm}$ thick for $2 \mathrm{~mL}$ of solution). Mixing and saturation of the solutions and wetting of the wall were facilitated by the presence of a glass stirring bar (about $14 \mathrm{~cm}$ long and $0.3 \mathrm{~cm}$ in diameter) that rested on the bottom of the rotating cylinder. Mixtures of nitrogen and water vapor in equilibrium with the composition of the acid solutions were used as carrier gas at a total flow rate of 100260 STP $\mathrm{cm}^{3} \mathrm{~min}^{-1}$ (STP conditions: $273 \mathrm{~K}$ and $1 \mathrm{~atm}$ ), a total pressure $P=65-170$ Torr $(0.08-0.23 \mathrm{~atm})$, and temperatures of $273-313 \mathrm{~K}$. The organic compounds were introduced into the main flow of the reactor by entraining their vapor into a small flow ( $\sim 10 \mathrm{STP} \mathrm{cm}^{3} / \mathrm{min}$ ) of $\mathrm{N}_{2}$ and sending this flow through a movable glass injector centered in the rotating cylinder. The movable injector allowed for the variation of the contact between the gas and liquid surfaces.

Uptake into (and desorption from, for solubility) the solutions was studied by monitoring variations in the gas-phase concentration of the organic. This concentration was monitored by sampling the flow with a proton transfer mass spectrometer (a form of CIMS). More detail on this instrument has been published elsewhere, ${ }^{20}$ and a basic description of it follows. It consists of a differentially pumped quadrupole mass spectrometer coupled to an ion drift tube. The ion drift tube was typically maintained at 10 Torr for this study. The ion source region produces the reagent ions $\mathrm{H}_{3} \mathrm{O}^{+}\left(\mathrm{H}_{2} \mathrm{O}\right)_{n}$, and these ions enter the drift tube region where they react with the organic compounds. Such proton transfers are known to be facile for organic compounds and allow for the detection of oxygenated and unsaturated species. ${ }^{21} \mathrm{MVK}$ and MACR, both of molecular weight 70 , were monitored at $\mathrm{M} \cdot \mathrm{H}^{+}$and $\mathrm{M} \cdot \mathrm{H}_{3} \mathrm{O}^{+}$at 71 and 89 amu, respectively. While for most organic compounds typical proton transfer conditions do not lead to extensive fragmentation, alcohols are the exception, and extensive dehydration can occur. The ionization of MBO (molecular weight 86) leads nearly exclusively to an ion of molecular weight of $\mathrm{M} \cdot \mathrm{H}^{+}-\mathrm{H}_{2} \mathrm{O}$ at 69 amu for our operating conditions. In room-temperature experiments, the temperature inside the reactor was assumed to be equal to that of the room, $296 \pm 2 \mathrm{~K}$, measured with a mercury thermometer. In the experiments at 273 and $313 \mathrm{~K}$, a water/ethanol mixture was flowed through the external jacket of the reactor and thermostated to within $\pm 1 \mathrm{~K}$.

A limited number of experiments were performed at the University of Miami using a similar RWW setup but coupled to a commercial HP 5971 electron ionization mass spectrometer. This setup was used to complete the investigation of the uptake of MVK and MACR in very concentrated solutions (90-96 wt $\left.\% \mathrm{H}_{2} \mathrm{SO}_{4}\right)$. Both compounds were monitored by ionization via electron impact at their parent ion at $70 \mathrm{amu}$. The experimental conditions were otherwise identical to the other RWW experiments.

Uptake investigations proceeded as follows: First, the injector was placed at its maximum position downstream where the liquid was not exposed $(z=0 \mathrm{~cm}$ in Figure 1) to obtain the unperturbed concentration of organics in the system, used as baseline signal, $S_{0}$. Then, the injector was moved upstream to expose the liquid to the gas (maximum exposure $z=15 \mathrm{~cm}$ ). Reactive uptake was indicated by a constant (with time) offset between the baseline signal and the uptake signal, $S$ (Figure 2a). Transient signals first decreasing then returning to the baseline (Figure $2 b$ ) indicated that the organic compound partitioned reversibly between the gas and the liquid, and these experiments lead to evaluations of the Henry's law coefficients,
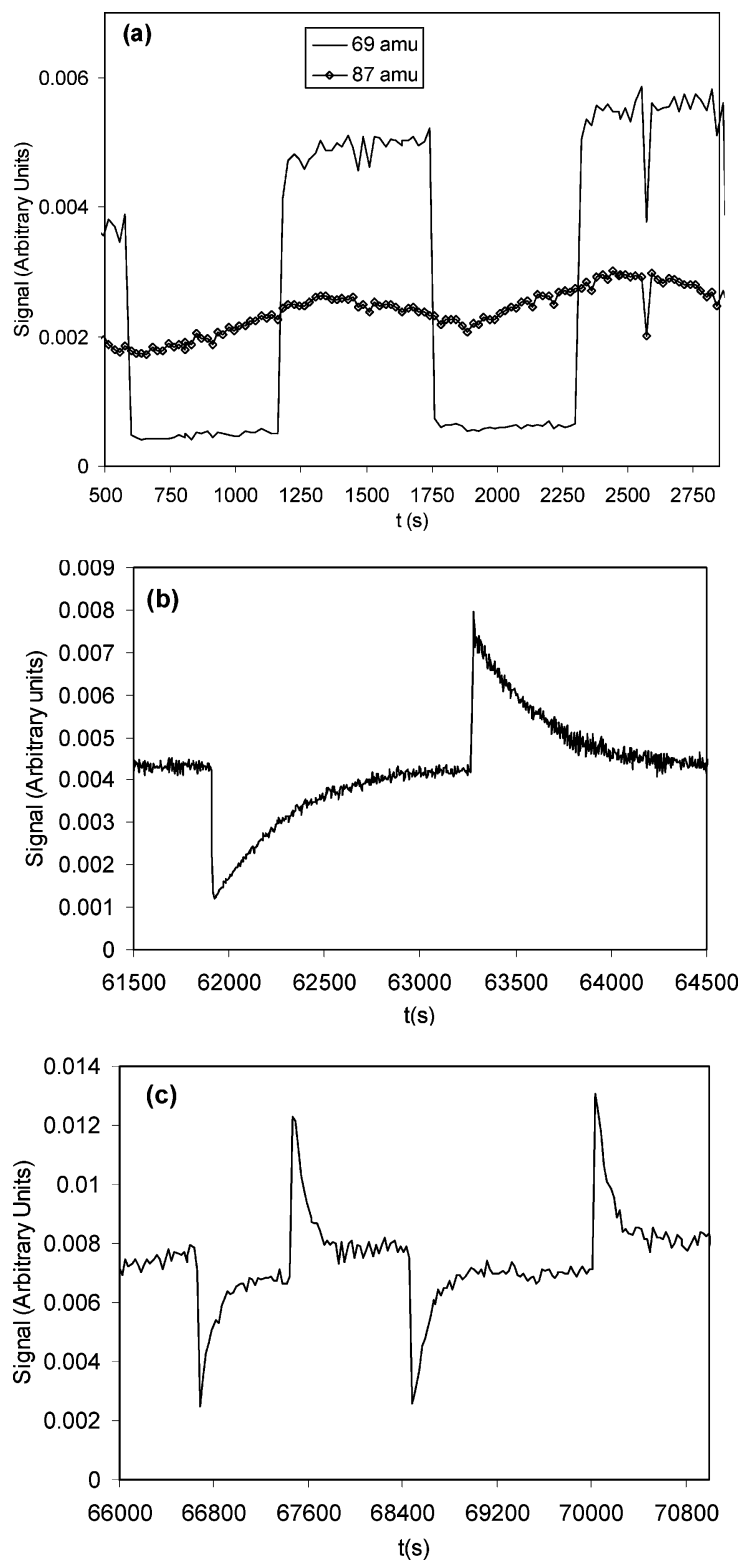

Figure 2. Typical experimental profiles. (a) Reactive uptake of MBO by $80 \mathrm{wt} \% \mathrm{H}_{2} \mathrm{SO}_{4}$ solution, observed at $69 \mathrm{amu}$, and release of a product at $87 \mathrm{amu}$. (b) Reversible uptake of MBO on water observed at 69 amu. (c) Combined reversible and potentially reactive uptake observed for MBO with 40 wt $\% \mathrm{H}_{2} \mathrm{SO}_{4}$ solution.

$H$. Returning the injector to its initial position after the uptake was completed, and observing a second transient signal indicated that molecules were desorbing from the liquid and confirmed the reversibility of the processes.

In a number of experiments (see Figure 2c), the variation of the signals indicated that two types of behavior were observed, e.g., a species was observed to be taken up and to desorb at a later time, but in addition, a constant offset of $1-10 \%$ in the asymptotic signal was observed at long exposure times. This could have been due to the occurrence of a slow reaction or to slight changes in the sensitivity of the instrument due to changes in water vapor content entering the CIMS. This small effect was mostly observed with solutions of moderate acidity and could have been caused by a change of sensitivity due to the flow of dry gas introduced by the injector, which represented $\sim 10 \%$ of the total flow. In experiments where reaction was seen to dominate, much larger changes (20\% or greater) were observed in the signals due to the exposure of reagent to the acid surface, and these are clearly identified with the occurrence 
of a reaction, as the changes were too large to be due to potential sensitivity changes.

Reactive Uptake. The first-order rate coefficient for removal of the organic compound from the gas phase, $k_{\mathrm{obs}}\left(\mathrm{s}^{-1}\right)$, was calculated from the reactive uptake signals, as

$$
\ln \left(\frac{S_{0}}{S}\right)=k_{\mathrm{obs}} L / v_{\text {ave }}
$$

where $L$ is the contact distance of the gas and the liquid $(3-15$ $\mathrm{cm})$, and $v_{\text {ave }}$ is the average carrier flow velocity $(6-16 \mathrm{~cm}$ $\left.\mathrm{s}^{-1}\right)$. Typically, the entire length of the RWW was exposed $(L=15 \mathrm{~cm}), v_{\text {ave }}$ was $6 \mathrm{~cm} \mathrm{~s}^{-1}$, and there is about a $3 \mathrm{~s}$ residence time of the carrier gas (and thus reactant) over the acid. For large uptakes, $k_{\text {obs }}$ was determined with more precision by placing the injector at various positions in the reactor. The effect of gas-phase diffusion on the uptake could be estimated by comparing $k_{\text {obs }}$ with the diffusion-limited rate $22,43,44$

$$
k_{\text {diff }}=\frac{3.6 D_{\mathrm{C}}}{\rho^{2}}
$$

where $\rho$ is the radius of the reactor and $D_{\mathrm{c}}$ is the diffusion

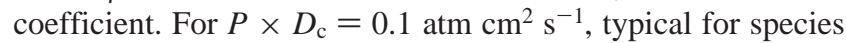
of this mass and size, our experimental conditions $(P=0.1-$ $0.25 \mathrm{~atm})$ were such that $k_{\text {diff }}$ ranged from $2-5 \mathrm{~s}^{-1}$; generally, $k_{\text {obs }}<k_{\text {diff }} / 2$. The surface rate constant for removal of the organic compound from the gas phase, $k_{\text {gas }- \text { surface, }}$ can be determined by correcting $k_{\mathrm{obs}}$ for diffusion ${ }^{44}$

$$
\frac{1}{k_{\text {gas }- \text { surface }}}=\frac{1}{k_{\text {obs }}}-\frac{1}{k_{\text {diff }}}
$$

A gas-surface reaction probability $\gamma$ can be obtained by dividing $k_{\text {gas-surface }}$ by the quantity $\omega / 2 \rho$, representing the firstorder gas-surface collision rate coefficient, ${ }^{45,46}$ where $\omega$ is the mean molecular speed of the reactant.

The first-order rate coefficient in solution, $k_{\text {liq }}^{\mathrm{I}}$, was estimated from the observed gas-phase rate using the relationship

$$
\mathrm{k}_{\text {liq }}^{\mathrm{I}}=\frac{V_{\text {gas }}}{V_{\text {liq }}} \times \frac{k_{\text {gas }- \text { surface }}}{H R T}
$$

where $V_{\text {gas }}$ is the volume of the reactor $\left(\sim 36.5 \mathrm{~cm}^{3}\right)$ in proximity to the liquid volume $\left(V_{\text {liq }}\right), R$ the gas constant, $T$ the temperature, and $H$ the Henry's Law coefficient of the organic compound in the solution. Equation 4 was derived on the assumption that the rates of mass transport (i.e., first-order diffusion rate in the gas-phase (eq 2) and the inverse of the mixing time due to stirring, $0.1 \mathrm{~s}^{-1}$ ) are much greater than the rates of reaction. It is tantamount to assuming that the reactor-liquid system can be thought of as an aerosol where each particle is a small reactor with a uniform concentration of reactant. With these assumptions, the entire volume of the solution contributes to the observed gas-phase loss. When these assumptions begin to be compromised, it is not clear how large an error is introduced, and any reported $k_{\text {liq }}^{\mathrm{I}}$ data are thus flagged. However, it seems that in the case where $k_{\text {liq }}^{\mathrm{I}}$ is greater than the liquid mixing time $\left(\sim 0.1 \mathrm{~s}^{-1}\right)$, the volume of liquid that contributes to the observed gas-phase loss is less than the total liquid volume, and $k_{\text {liq }}^{\mathrm{I}}$ from eq 4 is a lower limit to the true first-order rate coefficient in the liquid. Finally, the liquid-phase reaction rates determined by this method have another significant source of error, the uncertainty in the Henry's Law coefficient, $H$, which can be large especially when reactivity dominates and the value of $H$ can only be obtained via extrapolation.

Solubility Measurements. The processes responsible for reversible uptake include physical solubility and a species propensity to take other chemical forms via relatively rapid equilibria (also referred to as "speciation"). The sum total of these species concentrations in solution divided by the partial pressure of the parent species yields a value for the apparent Henry's law coefficients, $H$. Here, values for $H$ were determined from the experimental profiles using a method described earlier ${ }^{19,23}$

$$
H=\frac{F}{V_{\text {liq }}} \times \frac{I}{S_{0}} \times \frac{1}{R T}
$$

where $F$ is the total volumetric flow in the reactor $\left(\mathrm{cm}^{3} \mathrm{~s}^{-1}\right)$, $V_{\text {liq }}$ the volume of solution $\left(\mathrm{cm}^{3}\right)$, and $I / S_{0}(\mathrm{~s})$ is the integrated area of the uptake or desorption region in a signal vs time plot divided by the signal that is related to the partial pressure of reactant at saturation, $S_{0}$. These coefficients have been measured for MVK and MACR in sulfuric acid solutions at concentrations between 20 and $80 \mathrm{wt} \%$, and for MBO in water (277-295 K) and in 40 and 55 wt $\% \mathrm{H}_{2} \mathrm{SO}_{4}$.

The temperature dependence of the Henry's law coefficient of $\mathrm{MBO}$ in water was also determined by using a relative method described earlier. ${ }^{19}$ The volume of water was first exposed to MBO until it became saturated, and $S_{0}$ was noted. Then, the RWW was isolated, and all gas flows were stopped. The temperature was changed by about $10{ }^{\circ} \mathrm{C}$, and after $\sim 30$ min to let the system equilibrate, the gas flows were turned back on, the RWW was reconnected to the CIMS, and a new value for $S_{0}$ was noted that is related to the partial pressure of $\mathrm{MBO}$ at this temperature. The temperature was alternatively decreased and increased to check for loss of dissolved MBO (typically less than 20\%). The values of $S_{0}$, which are directly related to the partial pressure, are inversely proportional to the Henry's Law coefficient.

Bubble Column Experiments. Because thin films of pure water are sensitive to evaporation and difficult to maintain at room temperature in the RWW, a limited series of experiments were performed to measure the Henry's law coefficient for MVK in water using the bubble column technique. ${ }^{24}$ In this technique, known volumes of water containing a trace of MVK (approximately $10^{-3} \mathrm{M}$ ) were placed in a glass column through which a known volumetric gas flow could be maintained (standard gas flow rate, $Q=100-200 \mathrm{STP} \mathrm{cm}^{3} / \mathrm{min}$ at $P=$ 620 Torr). This induced a decrease of MVK concentration in both gas phase and solution because of the Henry's law equilibrium

$$
\ln \left(\frac{C_{0}}{C(t)}\right)=\ln \left(\frac{X_{0}}{X(t)}\right)=\frac{1}{V_{\text {liq }}} \frac{F}{R T H} \times t
$$

where $C(t)$ and $C_{0}$ are the concentrations of organic in the gas phase, $X(t)$ and $X_{0}$, the concentrations in the liquid phase, and $t$ the time. The concentration decay in the gas phase was monitored in real time with the CIMS instrument, and the Henry's law coefficient was obtained from the time constant of the decay.

Chemicals. MVK, MACR, and MBO (99\%, Aldrich), were used without further purification. Sulfuric acid solutions were prepared from 96.5 wt $\% \mathrm{H}_{2} \mathrm{SO}_{4}$ stock solutions (Mallinckrodt) and deionized water. Nitrogen was obtained from the vapor above liquid nitrogen. The organic compounds were obtained from their vapor over the pure liquids that were placed in a 
TABLE 1: Summary of the Henry's Law Coefficients Measured for MVK, MACR, and $\mathrm{MBO}^{a}$

\begin{tabular}{|c|c|c|c|c|}
\hline wt $\% \mathrm{H}_{2} \mathrm{SO}_{4}$ & $\begin{array}{l}H_{\mathrm{MVK}} \\
\mathrm{M} / \mathrm{atm}\end{array}$ & $\underset{\mathrm{s}^{-1}}{k_{\mathrm{liq}}^{\mathrm{I}}(\mathrm{MVK})}$ & $\begin{array}{l}H_{\mathrm{MACR}} \\
\mathrm{M} / \mathrm{atm}\end{array}$ & $\begin{array}{c}H_{\mathrm{MBO}} \\
\mathrm{M} / \mathrm{atm}\end{array}$ \\
\hline 0 & $22 \pm 1$ & & & $73 \pm 3$ \\
\hline $21 \pm 2$ & 12 & 0.005 & 80 & \\
\hline $20(273 \mathrm{~K})$ & 38 & $\sim 0$ & & \\
\hline $36 \pm 1$ & 35 & 0.0025 & & \\
\hline 40 & & & & $38 \pm 7$ \\
\hline 50 & 25 & 0.006 & & \\
\hline 52 & 25 & 0.009 & & \\
\hline 55 & 280 & 0.0011 & & $48 \pm 26$ \\
\hline 60 & 1500 & & 60 & \\
\hline 63.5 & 2200 & $<0.0001$ & & \\
\hline 70 & 7100 & $<0.00005$ & & \\
\hline 71.2 & & & 44 & \\
\hline $73(313 \mathrm{~K})$ & 3000 & - & & \\
\hline 80 & & $\leq 0.0003$ & 22 & \\
\hline
\end{tabular}

glass trap at $-77{ }^{\circ} \mathrm{C}$. Their vapor was entrained in a flow of nitrogen through the trap, and this flow was diluted before introduction into the injector. Typical organic concentrations in the flow reactor were $2 \times 10^{11}$ molecule $\mathrm{cm}^{-3}$, although occasionally, it was as high as $4 \times 10^{12}$ molecule $\mathrm{cm}^{-3}$. The acid content of the solutions were determined before and after each experiment by titration with standardized sodium hydroxide solutions.

\section{Results}

Uptake of MVK. The Henry's law coefficient of MVK in water measured by the bubble column technique was found to be $H_{\mathrm{MVK}}^{0}(296 \mathrm{~K})=(22.1 \pm 0.6) \mathrm{M} \mathrm{atm}^{-1}$, in good agreement with the previously reported value of $H_{\mathrm{MVK}}(298 \mathrm{~K})=(21.5 \pm$ 1) $\mathrm{M} \mathrm{atm}{ }^{-1},{ }^{25}$ but slightly lower than the one reported by another group of $H_{\mathrm{MVK}}(298 \mathrm{~K})=(41 \pm 7) \mathrm{M} \mathrm{atm}^{-1} .{ }^{26}$

The uptake of MVK measured with the RWW/CIMS setup was dominated by a reversible component in 20-73 wt \% sulfuric acid solutions, but was large and indicated no desorption from 80 to 96 wt $\% \mathrm{H}_{2} \mathrm{SO}_{4}$ solutions. The effective Henry's law coefficients for MVK were measured for sulfuric acid solutions between 20 and $73 \mathrm{wt} \%$, and the results are summarized in Table 1. A source of uncertainty in these measurements arises from discerning the asymptotic value in the signal vs time plots. An apparent steady-state loss in the more dilute solutions impacts the ability to discern the quantity $I / S_{0}$. Note that the $k_{\text {liq }}^{\mathrm{I}}$ values that could explain the measurements (see below) are very low, $<0.01 \mathrm{~s}^{-1}$, much less than the rotation rate of $\sim 0.1 \mathrm{~s}^{-1}$; thus, any potential loss within the liquids probably affects the quantity $I$, and thus the value of $H$, by less than $10 \%$. The values of the Henry's law coefficient for MVK rapidly increase with acid content starting near $55 \mathrm{wt}$ $\% \mathrm{H}_{2} \mathrm{SO}_{4}$ and reach values larger than the coefficient in pure water by 2 or more orders of magnitude.

The measured Henry's law coefficients for MVK, divided by the value in water at the same temperature, are presented in Figure 3 as a function of sulfuric acid content. Also shown are the Henry's law coefficients (divided by the values in water) for acetone $\left(295 \mathrm{~K},{ }^{27} 250 \mathrm{~K}^{15}\right)$, 2,4-pentanedione $\left(295 \mathrm{~K}^{27}\right)$, methanol $\left(231 \mathrm{~K}^{16}\right)$, butanol $\left(296 \mathrm{~K}^{28}\right)$, and acetaldehyde $(240$ $\mathrm{K}^{10}$ ). Like that for MVK, the $H$ values for these compounds also increase with acid content, although $H_{\mathrm{MVK}}$ appears to rise more steeply than those for the other species that have relatively simple molecular structures.

First-order removal rates from the gas phase, $k_{\mathrm{obs}}$, were determined from the observed decreases in the signals upon

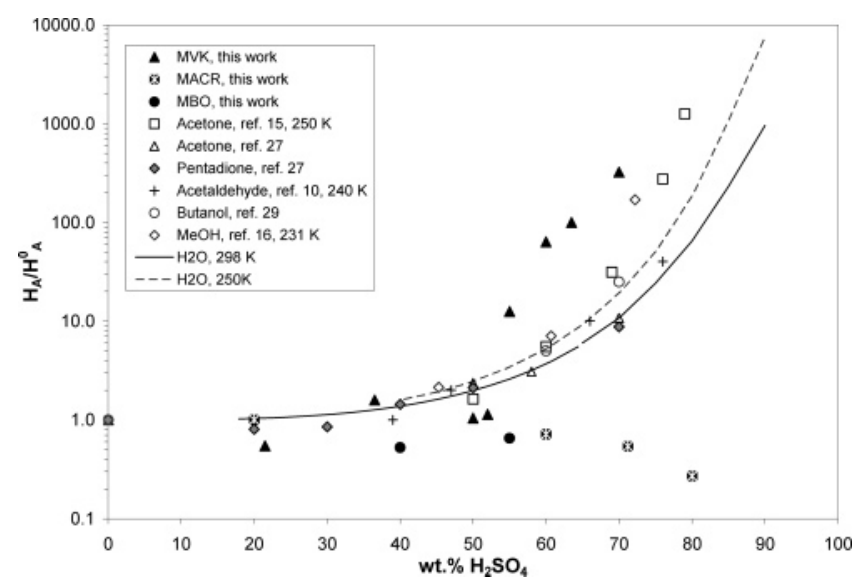

Figure 3. Henry's law coefficient $H_{\mathrm{A}}$ of MVK, MACR, and MBO, normalized to the values in pure water at the same temperature $\left(H_{\mathrm{A}}^{0}\right)$, as a function of sulfuric acid content. Data are for $296 \mathrm{~K}$ unless otherwise indicated. Also shown for comparison are the coefficients for acetone (ref 15, $250 \mathrm{~K}$; ref 27) and 2,4-pentanedione, ${ }^{27}$ acetaldehyde at $240 \mathrm{~K},{ }^{10}$ methanol at $231 \mathrm{~K}^{16}$, and butanol. ${ }^{29}$ Effective Henry's law coefficients for water are shown as the curved lines (solid, $298 \mathrm{~K}$; dashed, $250 \mathrm{~K}$ ); see the text for details.

exposure (the asymptotic signals, for the $20-55 \mathrm{wt} \%$ solutions) according to eq 1. First-order loss rate coefficients in solution, $k_{\text {liq }}^{\mathrm{I}}$, were calculated from eq 4 . For most of the solutions, the reactive component was difficult to discern in the signal vs time plots, because the asymptotic signal was, within the uncertainty, close to the unperturbed signal. Furthermore, we could not fully partition out potential sensitivity changes in the system, and we report most of the loss rates as upper limits.

The steady-state losses we report for MVK in 20-55 wt \% solutions were $10 \%$ or less of $S_{0}$; thus, changes in instrumental sensitivity upon exposure of the reactant to the liquid, due to the $\sim 10 \%$ changes in $\left[\mathrm{H}_{2} \mathrm{O}\right]$ entering the CIMS, could have been responsible for these "observed" losses. Yet, there is evidence that potential sensitivity changes are not responsible for the observed signal changes. The partial pressure of water ranges from 16 to 4.4 Torr over this range of acid content at $295 \mathrm{~K}$, and an uptake experiment in $20 \mathrm{wt} \%$ acid at $273 \mathrm{~K}$ $\left(\mathrm{H}_{2} \mathrm{O}\right.$ partial pressure $=4$ Torr $)$ showed no steady-state loss in signal. The different signal behavior for $20 \mathrm{wt} \%$ at $273 \mathrm{~K}$ versus 52 wt $\%$ at $296 \mathrm{~K}$, which exhibit similar $\mathrm{H}_{2} \mathrm{O}$ partial pressures, argues that sensitivity changes do not entirely explain the changes in the signals we observe, and that the steady state losses we report (but cannot identify; see below) decrease strongly with temperature. Plotted in Figure 4 is the observed gas-phase loss rate coefficient, $k_{\mathrm{obs}}$, versus the volume of the liquid in the RWW for the measurements on $36 \mathrm{wt} \% \mathrm{H}_{2} \mathrm{SO}_{4}$. $k_{\text {obs }}$ is clearly related to the volume of liquid in the RWW, and the slope of the line (from application of eq 4) yields a value for $k_{\text {liq }}^{\mathrm{I}}$ of $0.0025 \mathrm{~s}^{-1}$. Also, these data further support our attribution of the observed steady-state signal changes to a liquid-phase loss process. Thus, also presented in Table 1 are the $k_{\text {liq }}^{\text {I }}$ estimated from eq 4 . The upper limit value in $80 \mathrm{wt} \%$ acid $\left(k_{\text {liq }}^{\mathrm{I}}<0.0003 \mathrm{~s}^{-1}\right)$ rests on a lower limit to $H_{\mathrm{MVK}}$ of $10^{4}$ $\mathrm{M} \mathrm{atm}^{-1}$, because extrapolation $\left(H_{\mathrm{MVK}} / H_{\mathrm{MVK}}^{0}\right.$, Figure 3$)$ to 80 wt $\%$ is highly uncertain.

Scans of the CIMS over a wide range of masses revealed that no other compounds were detectable in the gas phase. This suggests that the potential reaction products were either partitioned to the liquid phase or not detectable with PT-MS. A potential reaction pathway that would lead to long-chain, large 


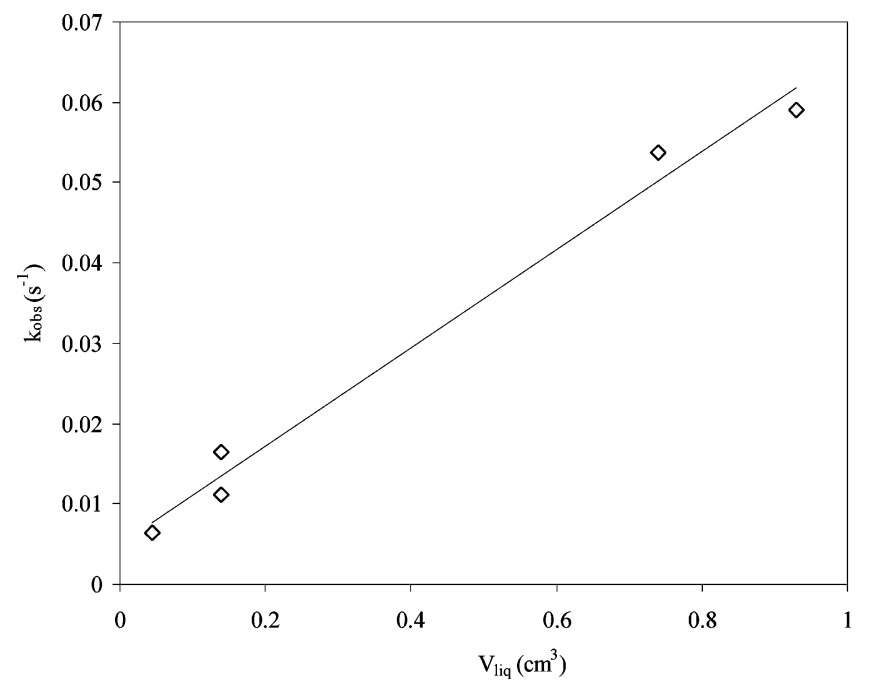

Figure 4. Steady state observed first-order gas-phase loss rate coefficient for MVK vs liquid volume in the reactor. Acid content was $36 \pm 1$ wt $\% \mathrm{H}_{2} \mathrm{SO}_{4}$, and temperature was $296 \mathrm{~K}$.

molecular weight products, is aldol condensation. Formation of the enol of MVK, 1,3-butadiene-2-ol, is an essential step in this process. Presented in the discussion are possible loss processes, but keep in mind that these values for $k_{\text {liq }}^{\mathrm{I}}$ in $20-55$ wt $\%$ acid could be considered phenomenological constants that merely explain the observations.

Uptake of MACR. The uptake of MACR was found to be reversible in sulfuric acid solutions up to $90 \mathrm{wt} \% \mathrm{H}_{2} \mathrm{SO}_{4}$. The effective Henry's law coefficient for this compound was measured between 20 and 80 wt $\% \mathrm{H}_{2} \mathrm{SO}_{4}$ solutions (Table 1 and Figure 3). Unlike that for MVK, this coefficient does not significantly change with acidity, and remains, perhaps decreasing slightly with acidity, near a value of $50 \mathrm{M} \mathrm{atm}^{-1}$.

The uptake of MACR was not reversible on the time scales of our experiments (a few hours) using 96 wt $\% \mathrm{H}_{2} \mathrm{SO}_{4}$ solutions. A first-order rate coefficient $k_{\text {gas-surface }}=\sim 2 \mathrm{~s}^{-1}$ was obtained for the reaction in $96 \mathrm{wt} \%$ solution, after correction for gas-phase diffusion (eq 3). Assuming a Henry's law coefficient of $50 \mathrm{M} \mathrm{atm}^{-1}$, a first-order liquid-phase reaction rate coefficient $k_{\text {liq }}^{\mathrm{I}}$ is estimated to be $\sim 10 \mathrm{~s}^{-1}$ (highly uncertain because $H_{\text {MACR }}$ is not known in 96 wt $\% \mathrm{H}_{2} \mathrm{SO}_{4}$, and the applicability of eq 4 is compromised at these loss rates.) As discussed below, MACR alone does not react by aldol condensation. No products were observed in the gas phase, precluding the identification of the reaction. Potential reactions in the highly acidic environment include hydrolysis, sulfation of a double bond, and reaction with $\mathrm{SO}_{3} .{ }^{7}$

Uptake of MBO. The uptake of MBO had both a timedependent (reversible) and constant (steady-state) component on 40 and $55 \mathrm{wt} \% \mathrm{H}_{2} \mathrm{SO}_{4}$ solutions (Figure 2c), whereas no reversible component was observed on $80 \mathrm{wt} \%$ acid, and a reaction product was detected. Extraction of the Henry's law coefficient of MBO from the measurements in $55 \mathrm{wt} \% \mathrm{H}_{2} \mathrm{SO}_{4}$ was difficult, because the reactive uptake was dominant over the reversible component. Furthermore, it was not possible to discern a reversible component in solutions more concentrated than $55 \mathrm{wt} \%$; thus, determination of $H$ was limited to the lowacidity, $0-55$ wt $\% \mathrm{H}_{2} \mathrm{SO}_{4}$ solutions. Table 1 and Figure 3 show that this coefficient does not increase significantly over this acidity range, remaining near the average of $50( \pm 20) \mathrm{M} \mathrm{atm}^{-1}$. The coefficient in water at room temperature was measured to be $H_{\mathrm{MBO}}^{0}(295 \mathrm{~K})=(73 \pm 3) \mathrm{M} \mathrm{atm}^{-1}$. Measurements as a
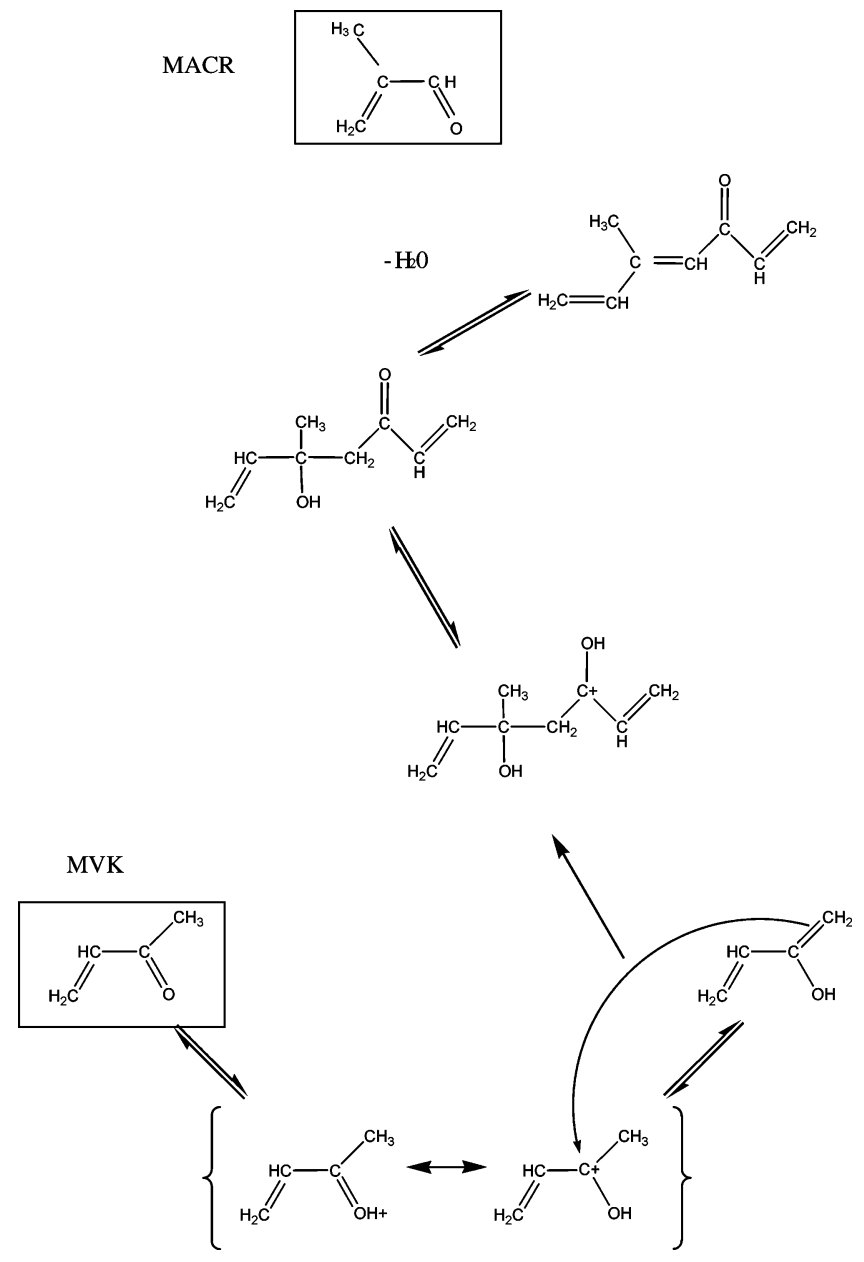

Figure 5. Structures of MACR and MVK and mechanisms of protonation, enolization, and aldol condensation for MVK.

function of temperature over $295-275 \mathrm{~K}$ showed that $H_{\mathrm{MBO}}^{0}$ increases exponentially with the inverse of temperature

$$
\ln \left[H_{\mathrm{MBO}}^{0}\right]=(7230 \pm 190) / T-(20.2 \pm 0.7)
$$

Errors in eq 8 are $1 \sigma$ precision from the fit. Total uncertainty in the slope is obtained by adding in a potential $10 \%$ systematic error (due to estimates of changes in the solutions with temperature) to get a value of $7230 \pm 900$ for the slope. This temperature effect corresponds to an enthalpy of solvation of $\Delta H_{\mathrm{sol}}=-(60 \pm 7) \mathrm{kJ} \mathrm{mol}^{-1}$, matching, within the uncertainties, the temperature dependence previously reported for the Henry's law coefficient of other alcohols. ${ }^{29}$ This temperature dependence leads to the value of $H_{\mathrm{MBO}}^{0}(303 \mathrm{~K})=54.5 \mathrm{M} \mathrm{atm}^{-1}$, slightly lower than that previously reported, $65( \pm 3.5) \mathrm{M} \mathrm{atm}^{-1}$, at this temperature. ${ }^{26}$

The first-order rate coefficient in the liquid was estimated from eqs 1-4. Assuming a constant Henry's law coefficient of $50 \mathrm{M} \mathrm{atm}^{-1}$ over the range $40-72$ wt $\% \mathrm{H}_{2} \mathrm{SO}_{4}$, gas-phase loss rates were converted into first-order liquid-phase reaction rates, $k_{\text {liq, }}^{\mathrm{I}}$, and plotted in Figure 6. This plot shows that the increase in $k_{\text {liq }}^{\mathrm{I}}$ with acid concentration can be explained by

$$
\ln \left(k_{\mathrm{liq}}^{\mathrm{I}}\right)=(0.19 \pm 0.02) \times W-(14.6 \pm 1.3)
$$

where $W$ is $\mathrm{H}_{2} \mathrm{SO}_{4}$ composition in weight percent. The data points for solutions greater than $62 \mathrm{wt} \%$ acid were not included in the fit, as the applicability of eqs 1-4 is compromised because of transport issues detailed above. Another reason for limiting 


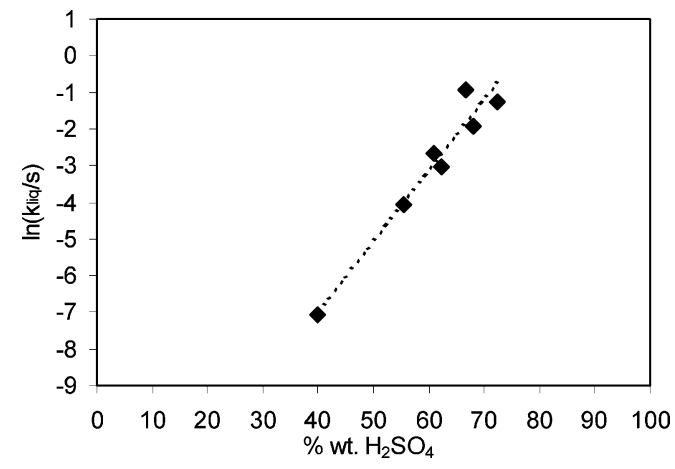

Figure 6. Liquid-phase first-order loss rate constant for $\mathrm{MBO}$ as function of the $\mathrm{H}_{2} \mathrm{SO}_{4}$ content of the solutions.

the fit to the less concentrated solutions is the possible occurrence of a large increase in the Henry's law coefficient with acid content for solutions of $60 \mathrm{wt} \%$ and larger.

Scanning the CIMS over 0-200 amu during the uptake experiments on $80 \mathrm{wt} \%$ acid showed that the formation of a compound that gives 87 amu after proton transfer was correlated with the uptake of MBO recorded at 69 amu (Figure 2a), with a significant delay in time due to its solvation. The signal at 87 amu was thus identified as due to a reaction product for uptake into $80 \mathrm{wt} \% \mathrm{H}_{2} \mathrm{SO}_{4}$. For the 40 and $55 \mathrm{wt} \%$ uptake experiments, there was little or no change in the $87 \mathrm{amu}$ signal upon exposure of MBO to the solutions.

\section{Discussion}

Henry's Law Coefficient of Oxygenated Organic Compounds in Sulfuric Acid. Previous reports show a large increase of the Henry's law coefficients with sulfuric acid content for carbonyl compounds such as acetaldehyde, ${ }^{10}$ acetone, ${ }^{15,27}$ and 2,4-pentanedione, ${ }^{27}$ as well as alcohols, such as methanol ${ }^{16}$ and butanol. ${ }^{28}$ The Henry's law coefficient for MVK measured in the present work displays a similar increase, while $H_{\mathrm{MACR}}$ is constant or slightly decreases over the same range. Because of the limited data available on the coefficient for $\mathrm{MBO}$, the latter will not be discussed here.

For species A partitioned between the gas and liquid phases, the Henry's law coefficient $H_{\mathrm{A}}$ is represented in this work as

$$
H_{\mathrm{A}}=[\mathrm{A}]_{\mathrm{tot}} / P_{\mathrm{A}}
$$

where $P_{\mathrm{A}}$ (in atm) is the partial pressure of $\mathrm{A}$ in the gas, and $[\mathrm{A}]_{\text {tot }}(M)$ is its total concentration in the liquid. At sufficiently low concentrations of dissolved $\mathrm{A}, H_{\mathrm{A}}$ is a constant according to Henry's law. At large concentrations of A, the properties of the liquid can be affected, yet an effective Henry's law coefficient can be used for the gas-solution equilibrium process, albeit not necessarily equal to $H_{\mathrm{A}}$ at low $[\mathrm{A}]_{\text {tot }}$. A large conventional Henry's law coefficient in an acidic solution is an indication that significant uptake of the compound may occur, even outside the range of applicability of the value of the conventional $H_{\mathrm{A}}$. The results of this work concerning these coefficients may contribute to the understanding of enhanced aerosol yields obtained with acidic particle seeds in recent smog chamber studies. $^{1-5}$ The comparison of $H_{\mathrm{MVK}}$ and $H_{\mathrm{MACR}}$ measured in this work leads to key questions concerning the processes responsible for the increase of these coefficients at high acidity: (i) Why do the Henry's law coefficients for MVK and MACR display such vastly different behavior with acidity? (ii) Why is the variation with acidity for MVK similar to the values reported previously for other carbonyl compounds and alcohols?
As in previous studies, ${ }^{10,15,16,27,28,30}$ the variations of the Henry's law coefficients with solution composition can be discussed semiquantitatively by taking into account the various forms that species A is thought to take in solution. Liquid-phase studies, such as for acetaldehyde, ${ }^{30}$ have established that carbonyl compounds undergo the following equilibria in acidic solutions:

(1) Protonation

$$
\mathrm{AH}^{+} \leftrightarrow \mathrm{A}+\mathrm{H}^{+} \quad K_{\mathrm{H}^{+}}=\frac{a_{\mathrm{A}} a_{\mathrm{H}^{+}}}{a_{\mathrm{AH}^{+}}}
$$

where $a_{i}$ is the activity of species $i$ in solution, and $K_{i}$ the equilibrium constant (note 11 is written as is customary and that $K_{\mathrm{H}^{+}}$is the equilibrium constant for the dissociation of the protonated ketone), and

(2) Enolization

$$
\mathrm{A} \leftrightarrow \text { enol } \quad K_{\text {enol }}=\frac{a_{\text {Enol }}}{a_{\mathrm{A}}}
$$

The molecular structures of protonated MVK and of the MVK enol are illustrated in Figure 5. An important difference between MVK and MACR is that MACR cannot form an enol because the carbon adjacent to the carbonyl is completely substituted.

In addition to equilibria (eqs 11 and 12), carbonyl compounds in acidic media can undergo the following reactions: ${ }^{31}$

(3) Addition of the protonated molecule onto the enol

$$
\mathrm{AH}^{+}+\text {enol } \rightarrow \mathrm{P}_{1} \quad\left(K_{\mathrm{add}}=\frac{a_{\mathrm{P} 1}}{a_{\mathrm{AH}^{+}} a_{\mathrm{enol}}}\right)
$$

which is essentially irreversible, and

(4) Dehydration of the addition product

$$
\mathrm{P}_{1} \leftrightarrow \mathrm{P}_{2}+\mathrm{H}_{2} \mathrm{O}
$$

Products P1 and P2 are also illustrated for MVK in Figure 5. Steps 11-14 constitute the aldol condensation mechanism. ${ }^{30}$ In our experiments with solutions of less than $80 \mathrm{wt} \% \mathrm{H}_{2} \mathrm{SO}_{4}$, the organic species were present at very low concentrations: typical gas-phase concentrations of $2 \times 10^{11} \mathrm{~cm}^{-3}\left(\sim 10^{-8} \mathrm{~atm}\right)$ and a maximum Henry's law coefficient of $10^{4} \mathrm{M} \mathrm{atm}^{-1}$ would correspond to a maximum liquid-phase concentration of $10^{-4}$ $\mathrm{M}\left(\sim 10^{-5}\right.$ mole fraction.) As discussed below, the rate constants for aldol condensation are generally small, and the rates of reaction are second order in the organic concentration. The low concentrations and small rate coefficients, therefore, imply that steps 13 and 14 were slow in the moderately strong acid solutions and likely had negligible impact on the equilibria (eqs 11 and 12).

Taking into account the protonated and enol forms, eq 10 becomes

$$
\begin{aligned}
& H_{\mathrm{A}}=\frac{[\mathrm{A}]_{\text {liq }}+\left[\mathrm{AH}^{+}\right]+[\mathrm{enol}]}{P_{\mathrm{A}}}= \frac{[\mathrm{A}]_{\mathrm{liq}}}{P_{\mathrm{A}}} \times \\
&\left(1+\frac{\left[\mathrm{AH}^{+}\right]}{[\mathrm{A}]_{\mathrm{liq}}}+\frac{[\mathrm{enol}]}{[\mathrm{A}]_{\mathrm{liq}}}\right)
\end{aligned}
$$

Note that other species, such as alcohols and small molecular weight aldehydes, ${ }^{8-10}$ can also have significant amounts of the hydrated forms in high water content solutions. We do not consider the hydrated form here, as the emphasis is on solutions 
with a significant acid content. Substituting the equilibrium constants into eq 15 leads to

$$
H_{\mathrm{A}}=\frac{[\mathrm{A}]_{\mathrm{liq}}}{P_{\mathrm{A}}} \times\left(1+\frac{1}{K_{\mathrm{H}^{+}}} \times \frac{a_{\mathrm{H}^{+}} \gamma_{\mathrm{A}}}{\gamma_{\mathrm{AH}^{+}}}+K_{\mathrm{enol}} \frac{\gamma_{\mathrm{A}}}{\gamma_{\mathrm{enol}}}\right)
$$

where $\gamma_{i}$ is the activity coefficient of species $i$.

Previous work focused on identifying the term in eq 16 (or an equivalent) responsible for the increase of $H$ at high acidity. This increase was first qualitatively attributed to the protonation terms for both methanol ${ }^{13}$ and acetone. ${ }^{15}$ Later work on ketones ${ }^{27}$ and acetaldehyde, ${ }^{10}$ using literature values for the protonation constants, concluded that the protonation term could not quantitatively explain the increase of the Henry's law coefficient with acidity. However, it is possible that the protonation constants reported in the literature cannot be applied to these strong acids or are flawed. Determination of many of these constants, and of the half-protonation points for alcohols, was based on distribution methods, ${ }^{7,31,32}$ which are essentially identical to the method used in this work: the relative measurement of the concentration of the organic species in two different phases. Using an equation equivalent to eq 16 without the enol term and assuming that solvent effects were negligible, half-protonation points for many alcohols were determined to be $\sim 45$ wt $\% \mathrm{H}_{2} \mathrm{SO}_{4}$. However, the activities of the various forms of an organic species and how they vary with acid content are not known: solvent effects cannot be assumed to be small (i.e., activity coefficients are not necessarily close to unity).

If we ignore potential artifacts in $K_{\mathrm{H}^{+}}$for the time being, the protonation constants for both the carbonyl species and the alcohols are reported to be in the range $10^{6}-10^{7} \mathrm{M}$ (e.g., $K_{\mathrm{H}^{+}}($acetone $\left.)=1.6 \times 10^{7} \mathrm{M}^{33}\right)$. MACR is expected to have a $K_{\mathrm{H}^{+}}$that is similar to that for other carbonyls and, in particular, for the present argument, to that for MVK. Thus, if protonation is responsible for the increase of Henry's law coefficients at high $\mathrm{H}_{2} \mathrm{SO}_{4}$ content, $H_{\mathrm{MACR}}$ should similarly increase at high acidity. The results of this work therefore allow us to make an important generalization in the understanding of these systems: While protonation might be an important step in the process responsible for the increase of Henry's law coefficient with acidity, it cannot be the sole cause for this behavior.

Because enolization constants are known to vary widely, between $K_{\text {enol }}=5 \times 10^{-9}$ for acetone, because of its low degree of substitution, to $K_{\text {enol }}=4$ for 2,4-pentanedione due to the stabilization of the enol by an internal hydrogen bond, ${ }^{6}$ it is also not easy to attribute increases in $H$ with acidity to the $K_{\text {enol }}$ term in eq 16. Most carbonyl compounds have a $K_{\text {enol }}$ several orders of magnitude larger than that of acetone; thus, it seems that enolization alone cannot be the reason for the increase in $H$ at high acidity for carbonyls $\left(K_{\text {enol }}=10^{-3}\right.$ being considered a fairly stable enol ${ }^{6}$ ). Yet, the similarities between increases in $H_{\text {MVK }}$ with acidity and that for the coefficients for acetaldehyde, acetone, methanol, and butanol, and the contrast with the behavior of $H_{\mathrm{MACR}}$, suggests an important contribution of the alcohol functionality of a compound to the value of $H_{\mathrm{A}}$ in concentrated acid.

In order for the enolization term in eq 16 to account for the observed increases of $H_{\mathrm{MVK}}$ between water and $\sim 70 \mathrm{wt} \%$ acid, the value of the equilibrium constant, $K_{\text {enol }}$, needs to increase with acidity, and/or the activity coefficient of the enol, $\gamma_{\text {enol }}$, has to decrease drastically with acidity compared to $\gamma_{\mathrm{A}}$. If the increase of $H_{\mathrm{MVK}}$ is due to a decrease of the activity coefficient of the enol, then an enhanced solvation of this molecule results from interactions with the solvent. Such an interaction could arise from coordination of $\mathrm{HSO}_{4}{ }^{-}$to the $\delta^{+}$on the carbon atom carrying the protonated hydroxyl group (a shielded carbonium atom $^{7}$ ). Enhanced solvation of the alcohols with increasing $\mathrm{H}_{2} \mathrm{SO}_{4}$ content could also be explained by such an interaction where the protonated alcohol leads to a partially solvated carbonium ion that can interact with $\mathrm{HSO}_{4}{ }^{-}$.

The first term in eq 16 could also be responsible for increases in $H_{\mathrm{A}}$ via physical interactions of $\mathrm{A}$ with the solvent at high acid content, similar to that alluded to for the alcohols having a significant interaction with the $\mathrm{HSO}_{4}{ }^{-}$ions in the solvent. This interaction may also be important for MVK and the carbonyls reported previously, while the lack of an interaction for MACR may be related to the fact that it does not enolize. Also shown in Figure 3 are the effective Henry's law coefficients for $\mathrm{H}_{2} \mathrm{O}$, normalized to the pure water value, obtained by applying eq 10 using the water content and the $\mathrm{H}_{2} \mathrm{O}$ vapor pressures of the acids, ${ }^{34,35}$ at 298 and $250 \mathrm{~K}$. The increase in this quantity occurs at similar acidities as those for the $H$ enhanced for many of the organic compounds. The similarity of the tendencies indicates the increase in $H_{\mathrm{A}}$ with acidity could be related to a solvation effect by $\mathrm{HSO}_{4}{ }^{-}$and/or another constituent of the solution.

Reactivity of Carbonyl Compounds (MVK, MACR) in Sulfuric Acid Solutions. As explained above, organic chemical studies have established that the main fate of carbonyl compounds in sulfuric acid solutions is aldol condensation. 6,7,30 Studies of the uptake of gas-phase acetone by strong sulfuric acid solutions (75-85 wt \%) for stratospheric purposes have confirmed the occurrence of this reaction by identifying specific products, mesityl oxide and trimethylbenzene. ${ }^{11}$

The reactive uptake of MVK in 80 and 96 wt \% acid solutions is thus likely to be due to aldol condensation. The reaction is second order, ${ }^{11,30,36}$ and a second-order reaction rate constant, $k_{\text {liq }}^{\mathrm{II}}$, can be obtained by dividing the values of $k_{\text {liq }}^{\mathrm{I}}$ obtained in this work by an estimated MVK liquid-phase concentration. However, because of the extrapolation of the Henry's law coefficient to concentrated solutions and the potential inapplicability of eq 4 due to large reactant gradients, large errors can be introduced in the values of both $k_{\text {liq }}^{\mathrm{I}}$ and $k_{\text {liq. }}^{\mathrm{II}}$. Therefore, we report only an estimate for loss rate coefficients that could explain our results and only for $80 \mathrm{wt} \% \mathrm{H}_{2} \mathrm{SO}_{4}$ solutions for which the error due to the extrapolation of the Henry's law coefficient would be the least and radial gradients within the liquid were small (although the first-order rate coefficient in the gas phase, $k_{\mathrm{obs}}$, was a significant fraction of $k_{\text {diff, }}$, introducing additional uncertainty in $k_{\mathrm{liq}}^{\mathrm{I}}$ ). Correcting $k_{\mathrm{obs}}$ for gas-phase diffusion lead to $k_{\text {gas }}=3 \mathrm{~s}^{-1}$. With a lower limit to $H_{\mathrm{MVK}}$ of $\sim 10^{4} \mathrm{M} \mathrm{atm}^{-1}$, we obtain $k_{\text {liq }}^{\mathrm{I}} \leq 3 \times 10^{-4} \mathrm{~s}^{-1}$ from eq (4.) With a typical mid-reactor value for gas-phase MVK of $\sim 10^{-8}$ atm, liquid-phase $[\mathrm{MVK}]$ is $\geq 10^{-4} \mathrm{M}$, and thus, a $k^{\mathrm{II}}$ of $\sim 3$ $\mathrm{M}^{-1} \mathrm{~s}^{-1}$ or less could explain the reactive uptake. This value is in the range of the rate constants recently estimated for other carbonyl compounds. ${ }^{36}$

Identifying a potential reaction of MVK in 20-55 wt \% solutions is not straightforward. Our observations indicate that $k_{\text {liq }}^{\mathrm{I}}$ was not dependent on $[\mathrm{MVK}]$ over this range (although this variation was over a range of only a factor of 2), which indicates first-order kinetics and is in contradiction with aldol condensation. Among the first of the processes that should be considered is enolization. Although $K_{\text {enol }}$ for MVK is not known, the reverse process of ketonization is probably fast, and if the enol is not scavenged, it will probably rapidly ketonize. It is possible that a low-level impurity in the acid solutions, such as a halide, on the order of $10^{-6}$ mole fraction, could have 
scavenged the enol form of MVK. We estimate that this scavenging reaction could have been maintained for several days for a typical rate of MVK consumption if the impurity were present in solution at $\sim 0.3 \mathrm{ppm}$. For $\mathrm{H}_{2} \mathrm{SO}_{4}$ contents of 20-55 wt $\%$, our observed first-order loss rates are in the range $0.002-$ $0.01 \mathrm{~s}^{-1}$ (properly, these are upper limits). These values are in the range of values previously determined for carbonyls. ${ }^{30}$

The postulations above notwithstanding, the reasons for the phenomenological $k_{\text {liq }}^{\mathrm{I}}$ in 20-55 wt $\% \mathrm{H}_{2} \mathrm{SO}_{4}$ solutions are not easily recognizable. Also, the rate coefficient estimated for MVK aldol condensation in $80 \mathrm{wt} \%$ acid rests on quantities with large uncertainties. Further experimental work is needed to ascertain a possible reaction in the dilute solutions and to obtain more accurate determinations of the reactivity in the strong solutions.

Recent work ${ }^{10}$ on the interaction of acetaldehyde with $\sim 47$ wt \% solutions $(210-240 \mathrm{~K})$ revealed a reactive component to the uptake. Although no rate coefficients were reported, this is in qualitative agreement with our observed losses for MVK in $20-55$ wt \% solutions. However, studies of acetone uptake using a RWW and an experimental setup similar to the present work ${ }^{15}$ reported no reactive component and very low upper limits $\left(10^{-4}\right.$ $\mathrm{M}^{-1} \mathrm{~s}^{-1}$ ) for the overall aldol condensation rate coefficient. It appears that the speciation and reactions of carbonyl compounds in sulfuric acid solutions are not easily generalized and can depend in complicated ways upon molecular structure, acidity, and temperature. Also, it appears that the effects of low-level impurities cannot be ruled out.

The lack of reactivity of MACR observed over most of the acidity range is likely due to the absence of enolization and aldol condensation. However, in the atmosphere, MACR could undergo aldol condensation as the protonated form with enols of other species. ${ }^{6}$ The reaction in 96 wt $\% \mathrm{H}_{2} \mathrm{SO}_{4}$ solution was not identified but would not be important in the atmosphere if it is confined to that extreme condition.

In conclusion, while aldol condensation produces, in principle, large molecular weight compounds, the results of this work are in agreement with previous work ${ }^{15,10}$ that this class of reactions should be very slow in typical atmospheric aerosol compositions and probably has only a marginal contribution to the formation of organic content of atmospheric aerosols.

Reactivity of MBO. In strong acid solutions, the reaction product of $\mathrm{MBO}$ observed at $87 \mathrm{amu}$ indicates the potential occurrence of a pinacol rearrangement. ${ }^{7}$ Pinacol rearrangement (initiated by protonation of a double bond) has previously been observed for two isomers of MBO, 2-methyl-2-buten-1-ol and 3-methyl-3-buten-2-ol in 13\% sulfuric acid, leading to a mixture of 3-methyl-2-butanone and 2-methyl-1-butanal. ${ }^{37,38}$ Because this reaction has been observed to occur in weak acids, we believe that pinacol rearrangement is also responsible for the uptake we observed in 40 and $55 \mathrm{wt} \% \mathrm{H}_{2} \mathrm{SO}_{4}$ solutions. A mechanism similar to the one proposed in the previous studies is shown in Figure 7 for MBO. The pinacol rearrangement of the protonated molecule of $\mathrm{MBO}$ could be favored by the formation of a carbonium ion carrying an oxygen atom, more stable than the initial secondary carbonium. The expected product of this rearrangement is 3-methyl-2-butanone. This transformation is essentially irreversible and can account for the observed consumption of MBO.

Dehydration of protonated MBO can occur spontaneously by the release of $\mathrm{H}_{2} \mathrm{O}$ (or neat $\mathrm{MBO}$ might eliminate $\mathrm{OH}^{-}$, Figure 7). This leads to protonated isoprene in solution, similar to what happens in the gas phase in the ion drift tube where $\mathrm{MBO}$ is detected primarily at $69 \mathrm{amu}$, which can isomerize between the original tertiary carbonium ion (probably favored) and a primary

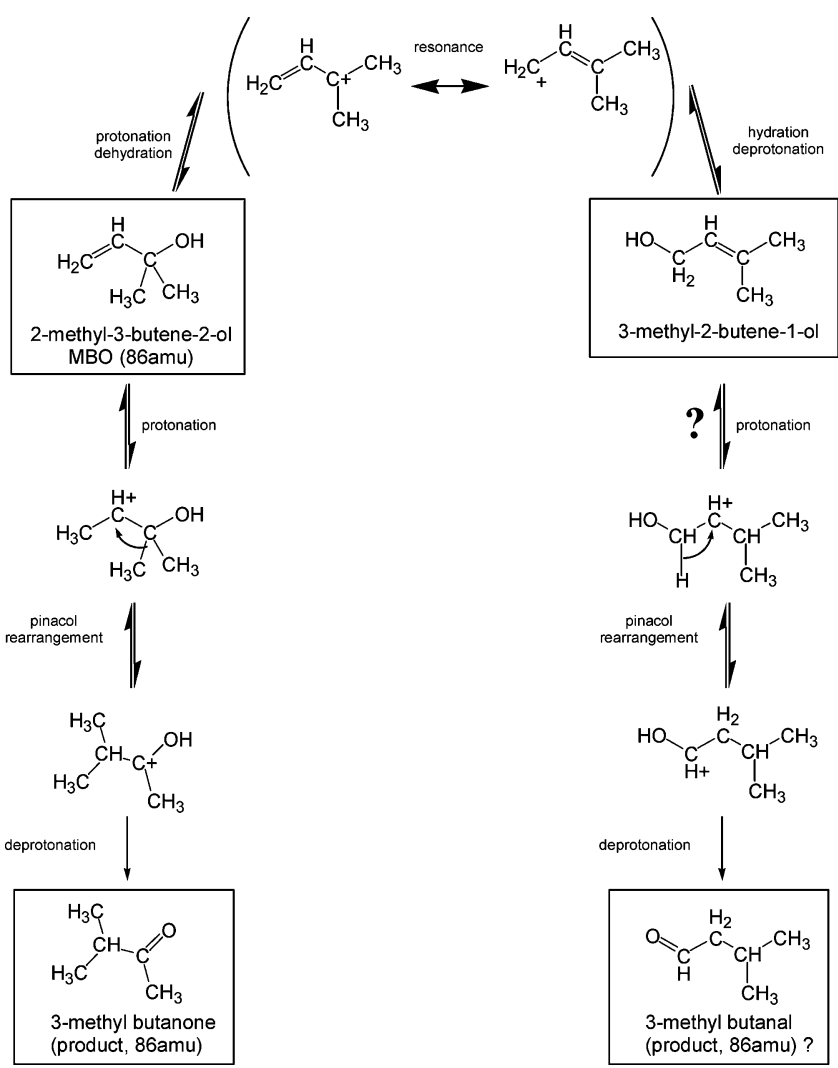

Figure 7. Mechanisms for pinacol rearrangements and isomerizations of $\mathrm{MBO}$.

carbonium ion with a $\beta$ double bond. Dehydration is reversible, and water molecules can add to either ion, giving 2-methyl-3butene-2-ol (MBO) or 3-methyl-2-butene-1-ol. The equilibrium between $\mathrm{MBO}, 3$-methyl-2-butene-1-ol, and protonated isoprene has been observed in 25-50 wt \% sulfuric acid solutions at 25 ${ }^{\circ} \mathrm{C} .{ }^{39-41}$ Both protonation and dehydration are reversible and can contribute to the effective $H$ for $\mathrm{MBO}$, but they are believed to be rapid and thus do not contribute to the observed irreversible uptake of MBO. 3-methyl-2-butene-1-ol is also likely to undergo pinacol rearrangement, which would potentially lead to 3-methylbutanal. This compound should however be less abundant than 3-methyl-2-butanone, since the equilibrium between $\mathrm{MBO}$ and 3-methyl-2-butene-1-ol is in favor of MBO. The existence of two separate products could not be verified, since they would both be detected at $87 \mathrm{amu}$. Large time lags in variations of the 87 amu signal with movements of the injector indicate that these products are quite soluble in the acid solutions, in line with the large solubilities of carbonyls discussed here. Pinacol rearrangement is also known to occur for diols and keto-alcohols under similar conditions, ${ }^{7,8}$ and it is only one example of the many possible rearrangements for carbonium in acidic media.

The isomerization and rearrangement reactions of $\mathrm{MBO}$ observed in this work might also occur in the atmosphere and result in accumulation of organic molecules in aerosols. In addition, they could produce species that cannot be formed by gas-phase oxidation, and might help explain recent observations such as the presence of 2-methyltetrols in organic aerosols from the Amazonian forest, ${ }^{42}$ for example. The formation of these compounds by gas-phase processes is unlikely to account for the quantities found in aerosols, while the acid-catalyzed liquidphase reactions and isomerizations leading to highly soluble species, similar to what was observed in this work for $\mathrm{MBO}$, could be efficient formation pathways. 


\section{Conclusion}

The present work provides new information on the uptake of oxygenated organic compounds by sulfuric acid solutions and on the processes controlling uptake. Comparing the results for MVK and MACR indicated that the increase of Henry's law coefficients for most carbonyl compounds and alcohols could be explained by a common mechanism: the enhanced solvation of alcohol (or enol) groups by interaction with the solvent $\left(\mathrm{H}_{3} \mathrm{O}^{+}\right.$, sulfate, or bisulfate ions). This notion is consistent with some of the chemical mechanisms outlined for sulfate solvent effects on the rates of reactions. ${ }^{7}$ The increase of Henry's law coefficients with acidity would result in an enhanced partitioning of oxygenated organic compounds into acidic aerosols, such as was observed in chamber studies. However, the Henry's law coefficients for the compounds studied to date do not increase significantly for solutions below $50 \mathrm{wt} \% \mathrm{H}_{2} \mathrm{SO}_{4}$, which is the range of acidity explored in smog chamber studies.

The rate of reaction of MVK by aldol condensation in sulfuric acid, $k_{\text {liq }}^{\mathrm{II}}$, was estimated to be about $3 \mathrm{M}^{-1} \mathrm{~s}^{-1}$ or less in $80 \mathrm{wt}$ $\%$ solutions, and the reaction was facile only at high acidity (80-96 wt \% $\mathrm{H}_{2} \mathrm{SO}_{4}$ ). The aldol condensation reaction is thus likely to be slow for MVK in the atmosphere, in agreement with the results of previous studies of acetaldehyde ${ }^{10}$ and acetone. ${ }^{15,27}$ Aldol condensation in sulfuric acid-water solutions is not likely to be a significant pathway for the formation of organic tropospheric aerosols because of a limited acidity.

$\mathrm{MBO}$ was found to react significantly in $40-80 \mathrm{wt} \%$ sulfuric acid solutions, and the reaction was tentatively identified as a pinacol rearrangement. Reaction rates measured in this work show that rearrangement and isomerization of substituted alcohols in acidic media can be significant even for tropospheric conditions. Such reactions could also provide an explanation for the observation of compounds found in atmospheric aerosols that could not be explained by gas-phase oxidation processes.

Acknowledgment. B. N. thanks W. Esteve for carrying out additional uptake experiments for this study.

\section{References and Notes}

(1) Jang, M.; Kamens, R. M. Environ. Sci. Technol. 2001, 35, 4758. (2) Jang, M.; Czoschke, N. M.; Lee, S.; Kamens, R. M. Science 2002, 298,814 .

(3) Jang.; M.; Lee, S.; Kamens, R. M. Atmos. Environ. 2003, 37, 2125.

(4) Limbeck, A.; Kulmala, M.; Puxbaum, H. Geophys. Res. Lett. 2003, 30; doi: 10.1029/2003GL017738.

(5) Iinuma Y.; Boge O.; Gnauk T.; Herrmann, H. Atmos. Environ. 2004, 38,761 .

(6) Smith, M. B.; March, J. Advanced Organic Chemistry; J. Wiley and Sons: New York, 2001.

(7) Liler, M. Reaction mechanisms in sulfuric acid and other strong acid solutions; Academic Press: New York, 1971.

(8) Jayne, J. T.; Worsnop, D. R.; Kolb, C. E.; Swartz, E.; Davidovits, P. J. Phys. Chem. 1996, 100, 8015.
(9) Iraci, L. T.; Tolbert, M. A. J. Geophys. Res. 1997, 102, 16099.

(10) Michelsen, R. R.; Ashbourn, S. F. M.; Iraci, L. T. J. Geophys. Res. 2004, 109; doi: 10.1029/2004JD005041.

(11) Duncan, J. L.; Schindler, L. R.; Roberts, J. T. Geophys. Res. Lett. 1998, 25,631 .

(12) Duncan, J. L.; Schindler, L. R.; Roberts, J. T. J. Phys. Chem. B 1999, 103, 7247-7259.

(13) Kane, S. M.; Timonen, R. S.; Leu, M.-T. J. Phys. Chem. 1999, $103,9259$.

(14) Klassen, J. K.; Lynton, J.; Golden, D. M.; Williams, L. J. Geophys. Res. 1999, 104, 26355.

(15) Imamura, T.; Akiyoshi, H. Geophys. Res. Lett. 2000, 27, 1419.

(16) (a) Iraci L. T.; Essin A. M.; Golden D. M. J. Phys. Chem. A 2002, 106, 4054. (b) Kane, S. M.; Leu, M.-T. J. Phys. Chem. 2001, 105, 1411.

(17) Lovejoy E. R.; Huey, L. G.; Hanson, D. R. J. Geophys. Res. 1995, $100,18775$.

(18) Hanson, D. R.; Lovejoy, E. R. J. Phys. Chem. 1996, 100, 6397.

(19) Nozière, B.; Longfellow, C. A.; Henry, B. E.; Voisin, D.; Hanson, D. R. Geophys. Res. Lett. 2001, 28, 1965.

(20) Hanson, D. R.; Greenberg, J.; Henry, B. E.; Kosciuch, E. Int. J. Mass Spectrom. 2003, 223-224, 507.

(21) Lindinger, W.; Hansel, A.; Jordan, A. Int. J. Mass. Spectrom. Ion Processes 1998, 173, 191.

(22) Murphy, D. M.; Fahey, D. W. Anal. Chem. 1987, 59, 2753.

(23) Hanson, D. R.; Ravishankara, A. R. J. Phys. Chem. 1993, 97, 12309.

(24) Betterton, E. A. Atmos. Environ. 1991, 25A, 1473.

(25) Allen, J. M.; Balcavage, W. X.; Ramachandran, B. R.; Shrout, A. L. Environ. Toxicol. Chem. 1998, 17, 1216.

(26) Iraci, L. T.; Baker, B. M.; Tyndall, G. S.; Orlando, J. J. J. Atmos. Chem. 1999, 33, 321 .

(27) Nozière, B.; Riemer, D. Atmos. Environ. 2003, 37, 841.

(28) Hanson, D. R.; Eisele, F.; Ball, S. M.; McMurry, P. Aerosol Sci. Technol. 2002, 36, 554 .

(29) Sander, R. Compilation of Henry's Law Constants for inorganic and organic species of potential importance in environmental chemistry, version 3; http://www.mpch-mainz.mpg.de/ sander/res/.

(30) Baigrie, L. M.; Cox, R. A.; Slebocka-Tilk, H.; Tencer, M.; Tidwell, T. T. J. Am. Chem. Soc. 1985, 107, 3640.

(31) (a) Arnett E. M.; Anderson, J. N. J. Am. Chem. Soc. 1963, 85, 1542. (b) Arnett E. M.; Wu, C. Y.; Anderson, J. N.; Bushick, R. D. J. Am. Chem. Soc. 1962, 84, 1674.

(32) Jaques, D.; Leisten, J. A. J. Chem. Soc. 1964, 2683.

(33) Deno, N. C.; Wisotsky, M. J. J. Am. Chem. Soc. 1963, 85, 1735.

(34) Clegg, S. L.; Brimblecombe, P.; Wexler, A. S. J. Phys. Chem. A 1998, 102, 2137.

(35) Weast, R. C., Ed. CRC Handbook of Chemistry and Physics; CRC Press Inc.: Boca Raton, FL, 1979.

(36) Esteve, W.; Nozière, B. J. Phys. Chem. A 2005, 109, 10920.

(37) Hearne, G.; Tamele, M.; Converse, W. Ind. Eng. Chem. 1941, 33, 805 .

(38) Currell, D.; Fry, A. J. Am. Chem. Soc. 1956, 78, 4377.

(39) Ryabova, R. S.; Osipova, G. F. Russ. Chem. Bull. 1994, 43, 311.

(40) Ryabova, R. S.; Osipova, G. F.; Vinnik, M. I. Bull. Russ. Acad. Sci. - Chem. 1992, 41, 1021.

(41) Ryabova, R. S.; Osipova, G. F.; Travin, S. O. Russ. Chem. Bull. 1995, 44, 840 .

(42) Claeys, M.; Graham, B.; Vas, G.; Wang, W.; Vermeulen, R.; Pashynska, V.; Cafmeyer, J.; Guyon, P.; Andreae, M. O.; Artaxo, P.; Maenhaut, W. Science 2004, 303, 1173.

(43) Hanson, D.; Burkholder, J. B.; Howard, C. J.; Ravishankara, A. R. J. Phys. Chem. 1992, 96, 4979.

(44) Gershenzon, Y. M.; Grigorieva, V. M.; Ivanov, A. V.; Remorov, R. G. Faraday Discuss. 1995, 100, 83.

(45) Kaufman, F. Prog. React. Kinet. 1961, 1, 1

(46) Howard, C. J. J. Phys. Chem. 1979, 83, 3. 